\title{
Exfoliation syndrome in Northern Nigeria
}

This article was published in the following Dove Press journal:

Clinical Ophthalmology

\section{Ugbede Idakwo' \\ Olusola Olawoye ${ }^{2}$ \\ Benedictus GK Ajayi' \\ Robert Ritch ${ }^{3}$}

'Eleta Eye Institute, Ibadan, Nigeria; ${ }^{2}$ Department of Ophthalmology, College of Medicine, University of Ibadan, Ibadan, Nigeria; ${ }^{3}$ Einhorn Clinical Research Center, Department of Ophthalmology, New York Eye and Ear Infirmary of Mount Sinai, New York, NY, USA
Correspondence: Olusola Olawoye Department of Ophthalmology, University College Hospital, PMB 5 I I6, Ibadan, Nigeria

Tel +2348023890063

Email solaolawoye@yahoo.com
Purpose: To estimate the frequency of exfoliation syndrome (XFS) and its association with ocular diseases in Northern Nigeria.

Materials and methods: Consecutive patients who presented to the outpatient department of ECWA Eye Hospital Kano from February 2015 to May 2015 were included in the study. Each patient had a complete ophthalmic examination. The anterior segment examination included tonometry, gonioscopy, and detailed slit-lamp examination to assess for the presence or absence of exfoliation material, inflammatory cells, and other abnormal findings. Patients with exfoliation material on the anterior lens surface and/or pupillary margin in either or both eyes were considered to have XFS. Statistical analysis was performed using the Statistical Package for the Social Sciences version 16.0.

Results: A total of 620 patients living in Northern Nigeria from the 6 geopolitical zones were examined. The majority of them $(34.5 \%)$ were indigenous Hausas. There was a male preponderance of $56.6 \%$, while the mean age at presentation for examination in all age groups was $55.7 \pm 13.7$ years. There were 9 patients with XFS; the frequency was $1.5 \%$, with most of the patients being 70-80 years old. In patients who were $\geq 50$ years, the frequency was $2.5 \%$. Patients with XFS had a higher mean age of $68 \pm 4.9$ years. The frequency of XFS among glaucoma patients was $4.4 \%$, while among cataract patients it was $3.7 \%$. No other associated ocular disease was found in the patients with XFS.

Conclusion: This study shows that XFS does exist in Northern Nigeria, as was found in the South. The prevalence of XFS was, however, not reported in the Nigerian National Blindness and Visual Impairment Survey. Therefore, a population-based study is still needed to determine the true prevalence of XFS in Northern Nigeria.

Keywords: exfoliation syndrome, glaucoma, cataract, Northern Nigeria, intra-ocular pressure

\section{Introduction}

Exfoliation syndrome (XFS) is an age-related, generalized disorder of the extracellular matrix characterized by production and progressive accumulation of a fibrillar material in tissues throughout the anterior segment and also in the connective tissue portions of various visceral organs. ${ }^{1}$ The disorder was first described by Lindberg in 1917 as grayish flecks on the pupillary border. ${ }^{2}$ These flecks are termed exfoliation material (XFM). XFS is the most common recognizable cause of open-angle glaucoma (OAG) worldwide $^{3}$ and can also cause angle-closure glaucoma (ACG). ${ }^{4}$

XFS has been considered rare in West Africa and among those of African descent in the Western Hemisphere, ${ }^{5}$ but this observation has begun to change in the last two decades. ${ }^{6,7}$ A recent review of XFS in sub-Saharan Africa showed that the burden of the disease is high in this region. ${ }^{8}$ Exfoliation glaucoma is often associated with high intraocular pressure (IOP), which can be very difficult to control, greater visual field (VF) loss, wider IOP variations, and more pronounced optic nerve damage as compared to primary open-angle glaucoma (POAG). ${ }^{3}$ Cataract surgery in patients with XFS is 
accompanied by an increase in complications such as lens subluxation, zonular dialyses or breaks, posterior capsular rupture, vitreous loss, subluxated intraocular lens, uveitis, hemorrhage, formation of posterior synechiae, and corneal endothelial decompensation. ${ }^{9}$

Despite the ocular associations of this condition, little work has been done in West Africa, making XFS poorly understood in the region. In Nigeria, a study done in the South-West by Olawoye et $\mathrm{al}^{6}$ had most of the patients from that geopolitical zone.

The Nigerian National Blindness and Visual Impairment Survey ${ }^{10}$ identified cataract and glaucoma as the leading causes of blindness in Nigeria, with the northern part of the country having the highest prevalence. This survey, however, did not report any case of XFS and exfoliation glaucoma. XFS was also not reported in another population-based study done in Ghana. ${ }^{11}$ To the best of our knowledge, no study has documented the prevalence and clinical characteristics of XFS in Northern Nigeria. We evaluated the prevalence and clinical characteristics of XFS in this region. This preliminary study provides relevant information and baseline knowledge which can be used to design a population-based study in the future.

\section{Materials and methods}

This was a prospective, cross-sectional study of patients attending ECWA Eye Hospital Kano. The study population comprised all patients aged $\geq 30$ years who attended ECWA Eye Hospital Kano for the first time between February 2015 and May 2015. Figure 1 shows the map of Nigeria depicting Kano and the other geopolitical zones in Nigeria. The study was guided by the tenets and principles of the Helsinki declaration. Ethical clearance for the study was sought and obtained from Catholic Hospitals' Ethical Committee based in Our Lady of Apostles Catholic Hospital, Oluyoro Oke-Ofa, Ibadan, before the commencement of the study. A letter of approval was sought and obtained from ECWA Eye Hospital Kano before the commencement of the study.

Patients 30 years and older who did not have any corneal disease which precluded clarity and proper examination of the anterior segment were included in the study. A written informed consent was obtained from all patients recruited into the study. Demographic characteristics such as age, sex, place of residence, educational status, and occupation were obtained from all patients. All patients had visual acuity test (unaided and aided) using standard illuminated Snellen's chart or illiterate E-chart (where necessary). All patients underwent

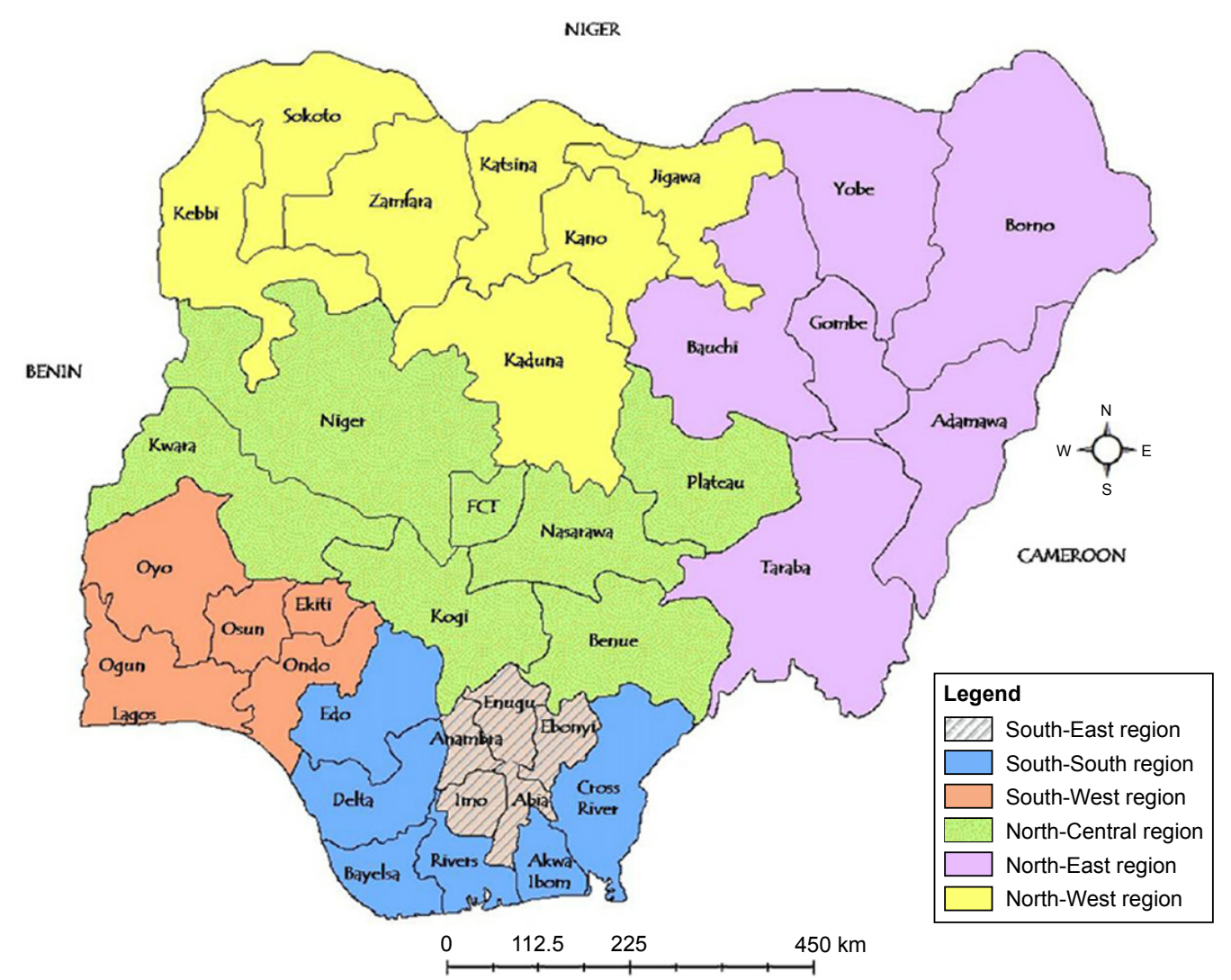

Figure I Map of Nigeria showing the six geopolitical zones.

Note: Reproduced from National Identity Management Commission. NIMC enrolment centres. Available from: https://www.nimc.gov.ng/nimc-enrolment-centres/. ${ }^{32}$ 
complete slit-lamp examination, applanation tonometry, and gonioscopy using Goldmann 3-mirror goniolens. The corneal endothelium was examined for the presence of XFM and pigment, as were the pupillary margin and anterior lens capsule. The width of the angle and iris configuration was assessed using the Shaffer grading system. ${ }^{12}$ Those with open angles were dilated with Mydriacyl and 2.5\% Phenylephrine and the anterior lens capsule was assessed in patients with pupillary dilatation of $\geq 6 \mathrm{~mm}$ to identify the central, intermediate, and peripheral zones of XFM deposition. IOP was also checked both prior to and after dilatation. The lens was assessed for the presence of cataract after pupillary dilatation and graded based on maturity and morphology using the World Health Organization classification ${ }^{13}$ and classified into cortical, nuclear, and posterior subcapsular cataract.
The vertical cup-to-disc ratio (CDR) was examined using the largest value of the cup superiorly from 11:00 to 1:00 o'clock and inferiorly from 5:00 to 7:00 o'clock positions under stereoscopic examination with the slit-lamp biomicroscope and a 78 diopter Volk lens. The optic nerve head was assessed for presence of thinning of neuroretinal rim, focal notching, saucerisation of the optic nerve head, retinal nerve fiber layer loss, and disc hemorrhage. Patients with findings suggestive of glaucoma underwent VF testing using the 24-2 SITA standard program on the Humphrey 740 visual field analyzer (Dublin, California, CA, USA). Patients with XFM in the anterior segment had photographs taken with an anterior segment camera (ChongQing KangHua RuiMing S\&T Model: SLM-4ER, ChongQing, People's Republic of China). Figure 2 shows the patient flow diagram.

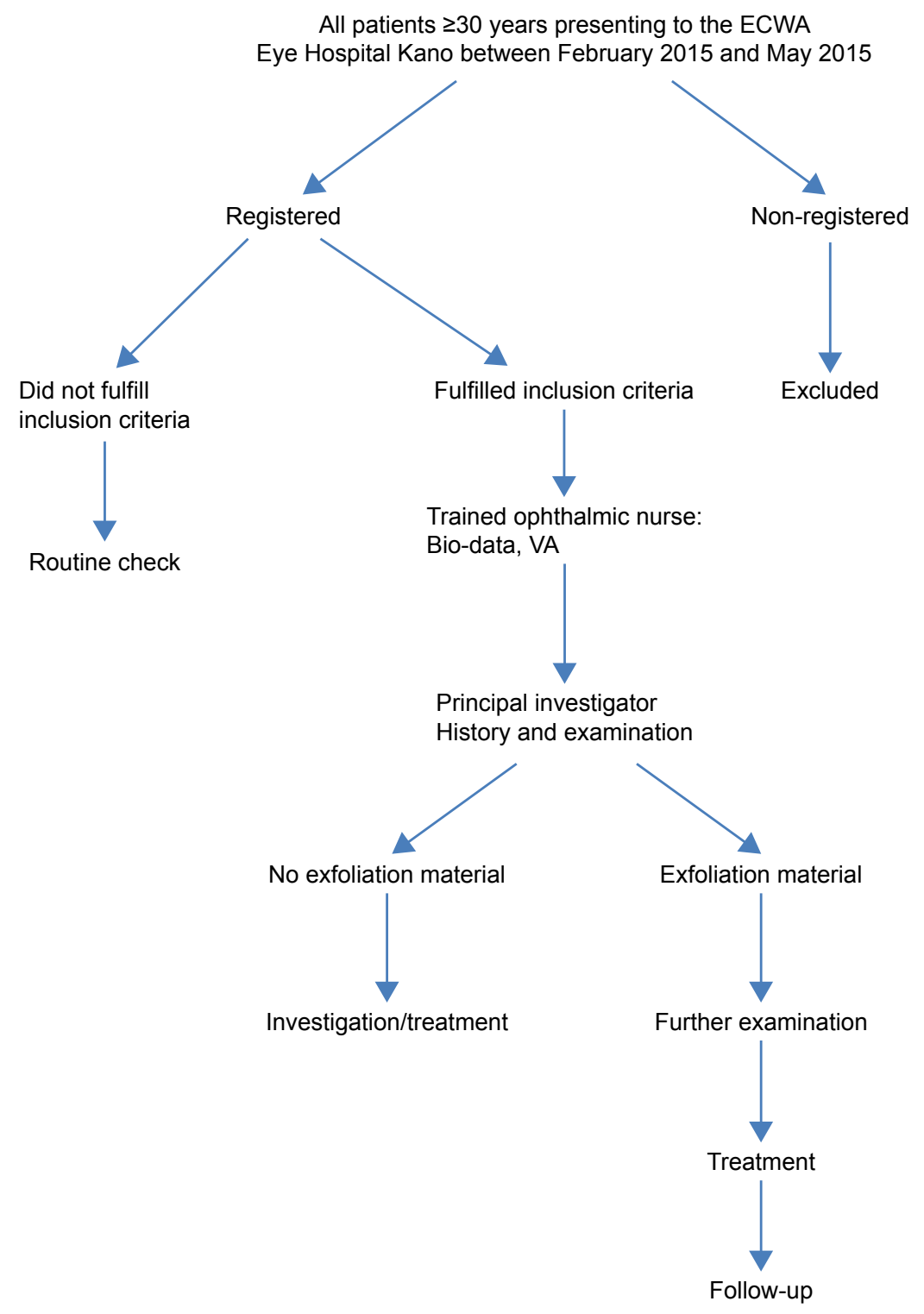

Figure 2 Patient flowchart. 


\section{Case definitions}

Using the American Academy of Ophthalmology Preferred Practice Pattern, ${ }^{14}$ POAG was defined as a chronic, progressive optic neuropathy in adults in which there is a characteristic acquired atrophy of the optic nerve and loss of retinal ganglion cells and their axons. This condition is associated with an open anterior chamber angle on gonioscopy. ${ }^{14}$

Glaucoma cases were identified using the International Society of Geographical and Epidemiological Ophthalmology ${ }^{15}$ criteria as follows:

- The highest level of evidence is eyes with optic disc abnormalities (vertical CDR [VCDR]) 97.5th percentile of the hyper-normal population and VF defects compatible with glaucoma, that is, eyes with VCDR $\geq 0.7 \mathrm{and} /$ or VCDR asymmetry $\geq 0.2$ or a neuroretinal rim width reduced to $\leq 0.1 \mathrm{CDR}$ (between 11:00 and 1:00 o'clock or 5:00 and 7:00 o'clock) that also shows definite VF defect consistent with glaucoma.

- A severely damage optic disc (VCDR 99.5th percentile of the hyper-normal population) if a VF test could not be performed satisfactorily. This means eyes with VCDR $\geq 0.9$ in which a VF could not be done satisfactorily.

- If the optic disc could not be examined because of media opacity (hence, no VF test was possible), then a visual acuity 20/400, IOP exceeding the 99.5 th percentile of the hyper-normal population $(26 \mathrm{mmHg})$, or evidence of previous glaucoma filtering surgery was taken as sufficient for a diagnosis of glaucoma.

\section{Results}

A total of 620 patients aged $\geq 30$ years were recruited into the study from the outpatient department of ECWA Eye Hospital Kano from February 2015 to May 2015. There were 351 males (56.6\%) and 269 females (43.4\%), with a male to female ratio of 1.3:1. The mean age was $55.7 \pm 13.7$ years (Table 1 ).

Of the total patients, $162(26.2 \%)$ had no formal education. There were 158 patients $(25.4 \%)$ with primary education, while 139 patients $(22.4 \%)$ were educated to a tertiary level and 92 patients (14.8\%) to a secondary level. Those with Quranic education were 69 patients (11.2\%) (Table 1).

Farming was practiced by the majority of patients, 176 (28.4\%). There were 27 teachers $(4.3 \%), 139$ traders $(22.5 \%)$, 97 civil servants $(15.6 \%)$, and 19 engineers (3.1\%). Other occupations including security guards, police, artists, and lawyers accounted for 162 patients $(26.1 \%)$.

The majority of patients, $419(67.6 \%)$, resided in the North-Western geopolitical zone followed by 77 (12.5\%) residing in the North-Eastern geopolitical zone, while
Table I Demographic distribution and frequency of the study group

\begin{tabular}{|c|c|c|}
\hline Parameters & Frequency $(\mathrm{N}=620)$ & Percentages \\
\hline \multicolumn{3}{|l|}{ Age (years) } \\
\hline $30-39$ & 103 & 16.6 \\
\hline $40-49$ & 154 & 24.8 \\
\hline $50-59$ & 170 & 27.4 \\
\hline $60-69$ & 138 & 22.3 \\
\hline 70-79 & 51 & 8.2 \\
\hline$\geq 80$ & 4 & 0.7 \\
\hline Total & 620 & 100.0 \\
\hline \multicolumn{3}{|l|}{ Sex } \\
\hline Male & 351 & 56.6 \\
\hline Female & 269 & 43.4 \\
\hline Total & 620 & 100 \\
\hline \multicolumn{3}{|l|}{ Education } \\
\hline None & 162 & 26.2 \\
\hline Primary & 158 & 25.4 \\
\hline Secondary & 92 & 14.8 \\
\hline Tertiary & 139 & 22.4 \\
\hline Quranic & 69 & 11.2 \\
\hline Total & 620 & 100 \\
\hline \multicolumn{3}{|l|}{ Geopolitical zone } \\
\hline North-West & 419 & 67.6 \\
\hline North-East & 77 & 12.5 \\
\hline North-Central & 59 & 9.5 \\
\hline South-West & 31 & 5 \\
\hline South-East & 17 & 2.7 \\
\hline South-South & 17 & 2.7 \\
\hline Total & 620 & 100 \\
\hline \multicolumn{3}{|l|}{ XFS } \\
\hline With & 9 & 1.5 \\
\hline Without & 611 & 98.5 \\
\hline Total & 620 & 100 \\
\hline
\end{tabular}

Abbreviation: XFS, exfoliation syndrome.

North-Central geopolitical zone had 59 patients (9.5\%). Those living in the South-West accounted for 31 patients (5\%), while the South-East was represented 17 patients (2.7\%) and South-South by 17 patients (2.7\%) (Table 1$)$.

The Hausas and Igbos formed the majority of the tribes of patients seen with $216(34.8 \%)$ and $126(20.3 \%)$ patients, respectively, while the Yorubas accounted for 64 (10.4\%), Fulani 61 (9.8\%), Kanuri 39 (6.3\%), and other tribes numbered $114(18.4 \%)$ patients.

Male patients formed the majority of the patients with XFS accounting for $77.8 \%(p<0.05)$. There were a total of 9 patients with XFS $(1.5 \%)$, and the mean age at presentation was $68 \pm 4.9$ years. The frequency of XFS in patients $\geq 50$ years was $2.5 \%$. Patients within the age group of 70-79 years had the highest prevalence of XFS (5.9\%). Table 2 shows the precise ages of the patients with XFS.

Of the 9 patients with XFS, 3 were Hausas, 2 were Kanuri, and there was 1 patient each from Fulani, Yoruba, Bantu, 
Table 2 Age distribution of 9 patients with XFS

\begin{tabular}{ll}
\hline Age (years) & Number with XFS \\
\hline 60 & 1 \\
65 & 3 \\
68 & 1 \\
69 & 1 \\
70 & 1 \\
75 & 2 \\
\hline
\end{tabular}

Abbreviation: XFS, exfoliation syndrome.

and Idoma tribes. All patients with XFS were residents of Northern Nigeria for the major part of their lives. There were 5 of 9 patients from the North-Western geopolitical zone accounting for $55.6 \%$ followed by the North-Eastern geopolitical zone with 3 (33.3\%) and North-Central with 1 (11.1\%). Furthermore, 8 patients $(88.9 \%)$ with XFS were full-time farmers, while one patient was a trader. Figure 1 shows the map of Nigeria depicting the different geopolitical zones.

XFS occurred in both eyes in 5 of the 9 patients (55.6\%). Two patients (22.2\%) had uniocular disease, while two others (22.2\%) had XFS in their only eyes, having lost one eye each to harmful traditional practice. XFS was seen in the right eye of the 2 patients with uniocular disease. All patients with XFS had XFM in the peripheral zones of the lens, while 8 patients had XFM on the pupillary margin. One patient had XFM on the lens and not on the papillary margin. Figure 3 shows the anterior segment photos of XFS.

There were 115 cases of glaucoma in the study population. The majority, $110(95.6 \%)$, were OAG while $5(4.4 \%)$
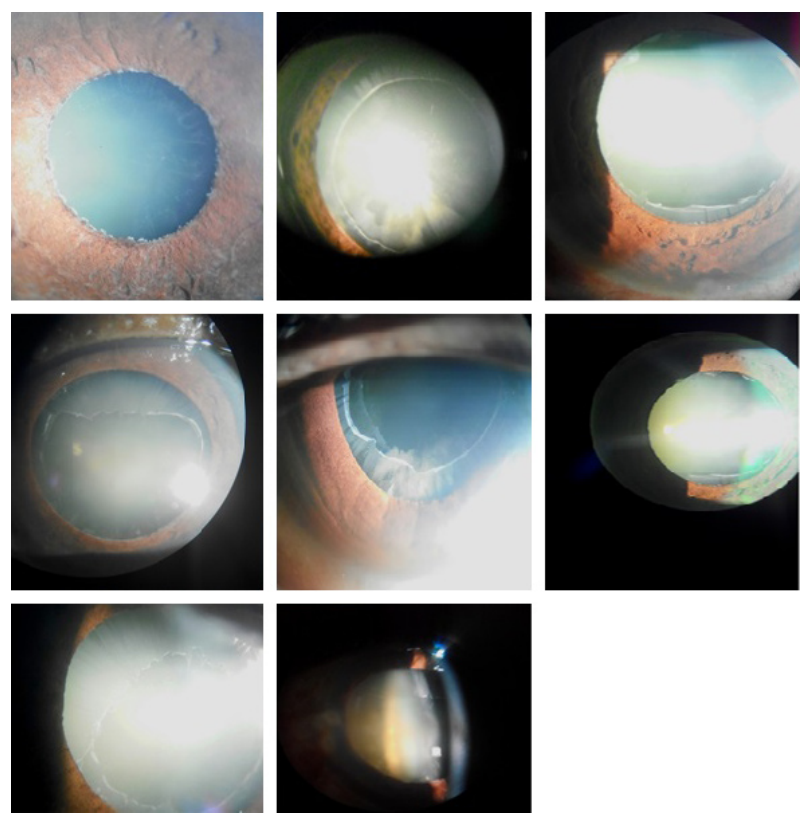

Figure 3 Anterior segment photos of exfoliation syndrome. had ACG. There were 106 (92.2\%) with bilateral glaucoma and $9(7.8 \%)$ with only one eye, the other eye having been lost to trauma, corneal opacity, or harmful traditional practices. Of the 9 patients with XFS, 5 (55.6\%) had OAG; there was no case of ACG. The frequency of XFS among glaucoma patients was $4.4 \%$. Two of the 5 patients with exfoliation glaucoma were on medical treatment prior to presentation with a mean IOP of $16.0 \mathrm{mmHg}$ OD and $13.0 \mathrm{mmHg}$ OS, while those not on medical treatment prior to presentation had mean IOP of $28.0 \mathrm{mmHg}$ OD and $24.7 \mathrm{mmHg}$ OS. The mean IOP for patients with XFS was $16.6 \pm 5.9 \mathrm{mmHg}$ OD and $18.9 \pm 6.0 \mathrm{mmHg}$ OS, while the mean IOP for patients without XFS in was $29.2 \pm 8.8 \mathrm{mmHg}$ OD and $30.8 \pm 8.6 \mathrm{mmHg}$ OS (Table 3).

There were 214 patients with cataract. Of this number, $160(74.8 \%)$ had cataract OU, 48 (22.4\%) had uniocular cataract, and $6(2.8 \%)$ had cataract in their only eyes. The total number of eyes with cataract was 374, of which 181 was OD and 193 OS.

Of the 9 patients with XFS, 4 had cataract only, 4 had cataract and glaucoma, and 1 patient had glaucoma only. Therefore, 8 patients had cataract, with 6 being bilateral and 2 having it in their only eyes, resulting in a total of 14 eyes; the 2 remaining eyes were blind at presentation. The frequency of XFS among cataract patients was 3.7\%. There were 3 eyes with mature cataracts, 11 with immature cataract, and one patient with XFS had no cataract. There were 8 eyes with nuclear sclerosis only, 2 eyes with posterior subcapsular cataract only, 2 eyes with both nuclear sclerosis and posterior subcapsular cataract, and 2 eyes with both cortical cataract and nuclear sclerosis. Nuclear sclerosis therefore occurred in 12 eyes of the patients with XFS. The patients with XFS that required surgery were operated by the most experienced ophthalmic surgeon in the hospital, and there was no perioperative complication.

\section{Discussion}

This report confirms the presence of XFS in Northern Nigeria. The frequency of XFS from our study was found to be $1.5 \%$, which is lower than the $2.7 \%$ reported in an earlier study in Southern Nigeria. ${ }^{6}$ There has been great variability shown by several studies in Africa; ${ }^{8}$ one reason for this may be the different populations studied as some of these studies were hospital based $^{6,7,16}$ while others were population-based studies. ${ }^{17,18}$ It may also be due to the wide difference in the sample size of the studies as well as the age range of individuals analyzed.

This study found a mean age of $55.7 \pm 13.7$ years in the study population and $68 \pm 4.9$ years among patients with XFS. 
Table 3 Mean IOP distribution with or without glaucoma in 620 patients

\begin{tabular}{|c|c|c|c|c|c|}
\hline & $\begin{array}{l}\text { XFS with } \\
\text { glaucoma }\end{array}$ & $\begin{array}{l}\text { XFS without } \\
\text { glaucoma }\end{array}$ & $\begin{array}{l}\text { All patients } \\
\text { with XFS }\end{array}$ & $\begin{array}{l}\text { All patients } \\
\text { without XFS }\end{array}$ & $\begin{array}{l}\text { Glaucoma } \\
\text { without XFS }\end{array}$ \\
\hline IOP OD $(\mathrm{mmHg})$ & $20.0 \pm 7.2$ & $14.0 \pm 3.7$ & $16.6 \pm 5.9$ & $20.4 \pm 8.7$ & $29.2 \pm 8.8$ \\
\hline IOP OS (mmHg) & $24.7 \pm 2.3$ & $14.5 \pm 3.0$ & $18.9 \pm 6.0$ & $21.0 \pm 9.2$ & $30.8 \pm 8.6$ \\
\hline
\end{tabular}

Notes: XFS without glaucoma: IOP in patients who had only exfoliation syndrome but did not have glaucoma. Glaucoma without XFS: IOP in patients who had glaucoma but did not have exfoliation syndrome.

Abbreviations: IOP, intraocular pressure; XFS, exfoliation syndrome.

This is similar to the study from Southern Nigeria ${ }^{6}$ with mean age of $65.6 \pm 5.6$ years in patients with XFS. The youngest age group recorded with XFS in Ethiopia ${ }^{17}$ is 47 years. Bartholomew ${ }^{18}$ reported that XFS appeared at an earlier age among the black South African population, with a prevalence of $6.4 \%$ among patients $30-39$ years of age. These differences in presentation might be related to genetic inheritance and nongenetic factors like ultraviolet light exposure. ${ }^{19}$ Early onset of XFS is however not particularly restricted to the African population alone as it has also been reported among Australian Aborigines, Icelanders, and Lapps. ${ }^{20}$ The youngest age among XFS patients in this study was 60 years, and the frequency increases with increasing age. For instance, the frequency of XFS in patients $\geq 40$ years in this report was $1.7 \%$, increasing to $4.7 \%$ in those $\geq 60$ years. McCarthy et $\mathrm{al}^{21}$ in Australia also reported a prevalence of $5.9 \%$ at 40 years, increasing to $12.7 \%$ among patients $\geq 60$ years. In a study in Egypt, ${ }^{22}$ patients aged $\geq 40$ years had a prevalence of $4.14 \%$, which increased to $5.77 \%$ in patients $\geq 60$ years. Similar studies from blacks in South Africa ${ }^{18}$ and South India ${ }^{23}$ showed progressive increase in incidence of XFS with age.

Men had a higher frequency of XFS compared to women. Compared to the frequency of men $(66.7 \%)$ in the study in Southern Nigeria, more men presented to the hospital in this current study (77.8\%). This is probably due to the difficulty faced by women in accessing health care in Northern Nigeria compared to the South. ${ }^{24}$ The male predilection in XFS in Nigeria is comparable to studies from the Aravind comprehensive eye survey ${ }^{25}$ where male gender is described as significantly associated with XFS. This could be due to men performing more outdoor activities compared with women. This finding is however contrary to that of the Reykjavik Eye Study, ${ }^{26}$ which had a higher prevalence in women.

It would be expected that Northern Nigeria with a higher latitude (latitude $12^{\circ} \mathrm{N}$ ) and increased annual sunlight compared to the South (latitude $7^{\circ} \mathrm{N}$ ), should have a higher frequency of XFS, but this was not the case. The study in the South reported a higher frequency. Similarly, Tanzania ${ }^{27}$ in the northern tier (latitude $6^{\circ} \mathrm{S}$ ) has no XFS compared to South Africa ${ }^{17}$ (latitude $30^{\circ} \mathrm{S}$ ), with a prevalence of XFS of $6.0 \%$ $7.7 \%$. Though environmental factors play a role in XFS, ${ }^{28}$ genetic factors could be a possible reason for this disparity. ${ }^{19} \mathrm{In}$ addition, the studies in the north and south of Nigeria are hospital-based studies and do not provide the true prevalence of the disease. The sample sizes in these studies were relatively small considering the low prevalence of XFS in Nigeria. A large population-based study would be necessary to determine the burden of the disease in Northern Nigeria.

In this study, the frequency of XFS among patients with cataract was $3.7 \%$, and nuclear cataract was the commonest form of cataract among patients with XFS (66.7\%). Several studies have shown that nuclear cataract is more often associated with XFS. ${ }^{29,30}$ This finding, however, is in contrast to findings from the Aravind Comprehensive Eye study ${ }^{25}$ where cortical cataract was found to be more common compared to nuclear sclerosis. This is probably due to the method of classification used in the study where mixed cataract was found to be the most common.

In this study, XFS was present in $4.4 \%$ of the patients with glaucoma. This is slightly higher compared to the incidence of $3.6 \%$ from Southern Nigeria ${ }^{6}$ and very close to the value from the Andhra Pradesh Eye Disease Study ${ }^{23}$ where the prevalence of XFS among glaucoma patients was $4.2 \%$. However, a higher frequency of $13.4 \%$ was reported in the Blue Mountain Study, ${ }^{31}$ and even higher values were obtained from the Scandinavian countries. ${ }^{20}$ Among the South African blacks, XFS accounted for $24.3 \%$ and $23.1 \%$ of the cases of OAG in Hlabisa and Temba, respectively. ${ }^{16}$ In this study, the presence of XFS was associated with OAG as $55.6 \%$ of XFS patients had established cases of OAG. This is slightly lower than that seen in the southern part of Nigeria where two-thirds of XFS patients had OAG. ${ }^{6}$

In the Reykjavik Eye Study, ${ }^{26}$ eyes with XFS had higher IOP than eyes without XFS. However, there was no direct relationship between IOP and XFS in this study as well as that of Southern Nigeria, as the mean IOP for glaucoma patients with XFS was lower than the mean IOP for glaucoma patients without XFS in both studies. In the Aravind Comprehensive Eye Survey, ${ }^{25}$ it was stated that IOP measurement cannot be relied upon primarily in testing for glaucoma. Rotchford et $\mathrm{al}^{16}$ also reported that some eyes with signs of XFS had IOP as low as $8 \mathrm{mmHg}$. 


\section{Conclusion}

XFS exists in Northern Nigeria as it does in the South. The disease was associated with increasing age. The prevalence of XFS is likely to increase as life expectancy of Nigerians increase. The majority of patients with XFS in this study were engaged in outdoor activities that exposed them to sunlight, indicating that environmental factors could play a role in XFS. Adequate mydriasis and slit-lamp biomicroscopy are essential in assessing the peripheral zone of the lens for exfoliation materials as subtle signs may be missed with poor pupillary dilatation.

This study was a preliminary and hospital-based study; therefore, a population-based study is required to determine the true prevalence of XFS in Northern Nigeria.

\section{Disclosure}

The authors report no conflicts of interest in this work.

\section{References}

1. Ritch R, Schlötzer-Schrehardt U, Konstas AG. Why is glaucoma associated with exfoliation syndrome? Prog Retinal Eye Res. 2003; 22:253-275.

2. Lindberg JG. Clinical Studies of Depigmentation of the Pupillary Margin and Transillumination of the Iris in Cases of Senile Cataract and also in Normal Eyes of the Aged [Thesis]. Helsinki, Finland: Helsinki University; 1917.

3. Ritch R. Exfoliation syndrome and occludable angles. Trans Am Ophthalmol. 1994;92:845-944.

4. Ritch R. Exfoliation syndrome-the most common identifiable cause of open-angle glaucoma. J Glaucoma. 1994;3:176-177.

5. Ball SF. Exfoliation syndrome prevalence in glaucoma population of South Louisiana. Acta Ophthalmol Suppl. 1988;184:93-98.

6. Olawoye OO, Ashaye AO, Teng CC, Liebmann JM, Ritch R, Ajayi BG. Exfoliation syndrome in Nigeria. Middle East Afr J Ophthalmol. 2012;19:402-405

7. Chuka-Okosa CM, Faal HB, Ogunro A, Duke R. Types of glaucoma and recent trends applied in treatment: Observation from a Glaucoma Training Workshop in the Gambia. Niger Postgrad Med J. 2005;12:203-209.

8. Olawoye OO, Pasquale LR, Ritch R. Exfoliation syndrome in subSaharan Africa. Int Ophthalmol. 2014;34(5):1165-1173.

9. Ritch R, Schlotzer-Schrehardt U. Exfoliation syndrome. Surv Ophthalmol. 2001;45:265-315.

10. Abdull MM, Sivasubramaniam S, Murthy GV, et al; Nigeria National Blindness and Visual Impairment Study Group. Causes of blindness and visual impairment in Nigeria: the Nigeria national blindness and visual impairment survey. Invest Ophthalmol Vis Sci. 2009;50(9):4114-4120.

11. Budenz DL, Barton K, Whiteside-de Vos J, et al. Prevalence of glaucoma in an urban West African population: the Tema Eye Survey. JAMA Ophthalmol. 2013;131(5):651-658.

Clinical Ophthalmology

\section{Publish your work in this journal}

Clinical Ophthalmology is an international, peer-reviewed journal covering all subspecialties within ophthalmology. Key topics include: Optometry; Visual science; Pharmacology and drug therapy in eye diseases; Basic Sciences; Primary and Secondary eye care; Patient Safety and Quality of Care Improvements. This journal is indexed on
12. Shaffer RN. Primary glaucomas. Gonioscopy, ophthalmoscopy, and perimetry. Trans Am Acad Ophthalmol Otolaryngol. 1960;64:112-127.

13. Thylefors B, Chylack LT Jr, Konyama K, et al; WHO Cataract Grading Group. A simplified cataract grading system. Ophthalmic Epidemiol. 2002;9:83-95.

14. American Academy of Ophthalmology Preferred Practice Pattern; 2015:49.

15. Foster PJ, Buhrmann R, Quigley HA, Johnson GJ. The definition and classification of glaucoma in prevalence surveys. $\mathrm{Br}$ J Ophthalmol. 2002;86:238-242.

16. Rotchford AP, Kirwan JF, Johnson GJ, Roux P. Exfoliation syndrome in black south Africans. Arch Ophthalmol. 2003;121:863-870.

17. Bedri A, Alemu B. Pseudoexfoliation syndrome in Ethiopian glaucoma patients. East Afr Med J. 1999;76:278-280.

18. Bartholomew RS. Pseudo-capsular exfoliation in the Bantu of South Africa. I. Early or pre-granular clinical stage. Br J Ophthalmol. 1971;55: 693-699.

19. Damji KF, Bains HS, Stefansson E, et al. Is pseudoexfoliation syndrome inherited? A review of genetic and nongenetic factors and a new observation. Ophthalmic Genet. 1998;19:175-185.

20. Forsius H. Prevalence of pseudoexfoliation of the lens in Finns, Lapps, Icelanders, Eskimos and Russians. Trans Ophthalmol Soc UK. 1979;99:296-298.

21. McCarthy CA, Taylor HR. Pseudoexfoliation syndrome in Australian adults. Am J Ophthalmol. 2000;129:629-633.

22. Shazly TA, Farrag AN, Kamel A, Al-Hussaini AK. Prevalence of pseudoexfoliation syndrome and pseudoexfoliation glaucoma in Upper Egypt. BMC Ophthalmol. 2011;11:18

23. Thomas R, Nirmalan PK, Krishnaiah S. Pseudoexfoliation in southern India: The Andhra Pradesh Eye Disease Study. Invest Ophthalmol Vis Sci. 2005;46(4):1170-1176.

24. Adedini SA, Odimegwu C, Bamiwuye O, Fadebiyi O, De Wet N. Barriers to accessing health care in Nigeria: implications for child survival. Global Health Action. 2014;7:23499.

25. Krishnadas R, Nirmalan PK, Ramakrishnan R, et al. Pseudoexfoliation in a rural population of Southern India: The Aravind Comprehensive Eye Survey. Am J Ophthalmol. 2003;135:830-837.

26. Arnarsson AM, Damji KF, Sverrisson T, Sasaki H, Jonasson F. Pseudoexfoliation in the Reykjavik Eye Study: prevalence and related ophthalmological variables. Acta Ophthalmol Scand. 2007;85:822-827.

27. Buhrmann RR, Quigley HA, Barron Y, et al. Prevalence of glaucoma in a rural East African population. Invest Ophthalmol Vis Sci. 2000;41: 40-48.

28. Stein JD, Pasquale LR, Talwar N, et al. Geographic and climatic factors associated with exfoliation syndrome. Arch Ophthalmol. 2011;129: 1053-1060.

29. Hietanen J, Kivela T, Vesti E, Tarkkanen A. Exfoliation syndrome in patients scheduled for cataract surgery. Acta Ophthalmol (Copenh). 1992;70:440-446.

30. Young AL, Tang WW, Lam DS. The prevalence of pseudoexfoliation syndrome in Chinese people. Br J Ophthalmol. 2004;88:193-195.

31. Mitchell P, Wang JJ, Hourihan F. The relationship between glaucoma and pseudoexfoliation: The Blue Mountain Eye Study. Arch Ophthalmol. 1999;117:1319-1324.

32. National Identity Management Commission. NIMC enrolment centres Available from: https:/www.nimc.gov.ng/nimc-enrolment-centres/.

\section{Dovepress}

PubMed Central and CAS, and is the official journal of The Society of Clinical Ophthalmology (SCO). The manuscript management system is completely online and includes a very quick and fair peer-review system, which is all easy to use. Visit http://www.dovepress.com/ testimonials.php to read real quotes from published authors. 